\title{
Pellets of MgH2-based Composites as Practical Material for Solid State Hydrogen Storage
}

G. Principi, A. Khandelwal, F. Agresti, G. Capurso, A. Maddalena, S. Lo Russo

This document appeared in

Detlef Stolten, Thomas Grube (Eds.):

18th World Hydrogen Energy Conference 2010 - WHEC 2010

Parallel Sessions Book 4: Storage Systems / Policy Perspectives, Initiatives and Cooperations

Proceedings of the WHEC, May 16.-21. 2010, Essen

Schriften des Forschungszentrums Jülich / Energy \& Environment, Vol. 78-4

Institute of Energy Research - Fuel Cells (IEF-3)

Forschungszentrum Jülich $\mathrm{GmbH}$, Zentralbibliothek, Verlag, 2010

ISBN: 978-3-89336-654-5 


\title{
Pellets of $\mathrm{MgH}_{2}$-based Composites as Practical Material for Solid State Hydrogen Storage
}

\author{
Giovanni Principi, Ashish Khandelwal, Filippo Agresti, Giovanni Capurso, \\ Amedeo Maddalena, Materials Section, Dept. of Mechanical Engineering, University \\ of Padova, Italy
}

Sergio Lo Russo, Dept. of Physics, University of Padova, Italy

\section{Introduction}

$\mathrm{MgH}_{2}$ is one of the most studied materials among those able to store hydrogen in solid state, having many assets in its favour, like low cost, abundance, light weight and a theoretical storage capacity of $7.6 \mathrm{wt} \%$. However, concerning the practical applications, it has the limitations of high thermodynamic stability and slow hydrogen absorption/desorption $(\mathrm{a} / \mathrm{d})$ kinetics. To come out of these practical shortcomings $\mathrm{MgH}_{2}$ is used in nano-crystalline form obtained by high energy ball milling mixed with transition metal oxides, e.g. $\mathrm{Nb}_{2} \mathrm{O}_{5}[1,2]$, acting as catalysts to improve the hydrogen a/d kinetics with little reduction in the gravimetric capacity. During scaling up studies of $\mathrm{MgH}_{2}$ based powders in a specially designed reactor it was observed that the hydrogen storage capacity, as well as the a/d kinetics, decreased with the ongoing cycles [3]. It was argued that this degradation was due to a close compaction of the powder particles inside the reaction chamber associated with local overheating, with the detrimental effect of strongly reducing the free flow of hydrogen through the storage material. The compaction of the powders was probably due to a pressure gradient that built up during the first stages of hydrogen absorption process given by the difficult gas transport through the $\mathrm{Mg}$ bed. These observations motivated us to study $\mathrm{MgH}_{2}$ based powders moderately pressed in the form of pellets with the addition of some binding agent in order to retain stable mechanical consistency and structure with persistent free paths for hydrogen diffusion. The use of pellets instead of powder should improve the hydrogen transport inside the storage vessel avoiding pressure gradients and further compaction of the material. Moreover, in principle, each pellet should behave as an independent system reducing scaling up effects on the a/d kinetics.

In this work we have tested $\mathrm{MgH}_{2}$ catalysed ball milled powders mixed with Al powder as a binder pressed with an electro-mechanical press, following an approach already preliminarily tested [4]. The crystalline structure, the hydrogen a/d properties and the mechanical strength of the samples have been analysed before and after hydrogen a/d cycling. The incorporation of aluminium is supposed also to enhance the thermal conductivity in the pellets.

\section{Experimental}

$\mathrm{MgH}_{2}$ powder mixed with $\mathrm{Nb}_{2} \mathrm{O}_{5}$ (5 wt \%) and graphite (1 wt\%), as catalysts of the gas-solid reaction, was ball-milled in a SPEX 8000 shaker mill for 20 hours using steel balls with ball to powder ratio of 10:1 (samples denoted as cat- $\mathrm{MgH}_{2}$ ). Two types of pellets were studied: one made up of as-milled cat- $\mathrm{MgH}_{2}$ powder and in the other case 5 and $20 \mathrm{wt} \%$ of Al powder was 
homogenously mixed by ball-milling for 5 min with cat- $\mathrm{MgH}_{2}$ to act as a binding agent (samples denoted as cat- $\mathrm{MgH}_{2}-\mathrm{Al} 5$ and cat- $\mathrm{MgH}_{2}-\mathrm{Al} 20$, respectively). All pellets were obtained by pressing the powders in Ar atmosphere with a uniaxial pressure of $180 \mathrm{MPa}$ by means of an Instron 1121 tester. Kinetic and thermodynamic tests were performed using a Sievert's type gas reaction controller. Annealing of samples containing Al powder was performed at $450{ }^{\circ} \mathrm{C}$ in the same Sievert's apparatus for $10 \mathrm{~min}$ under a rotary pump vacuum before starting the hydrogen a/d cycles. In order to test the compressive strength resistance of the pellets after different a/d cycles, compression tests were performed using the same Instron 1121 tester at the compressive strain rate of $1 \mathrm{~mm} / \mathrm{min}$. For all samples the hydrogen release processes were performed at the temperature of $320^{\circ} \mathrm{C}$ and $\mathrm{H}_{2}$ pressure of $1.2 \mathrm{~atm}$, while the soak processes were performed at the same temperature and $\mathrm{H}_{2}$ pressure of $15 \mathrm{~atm}$.

\section{Results and Discussion}

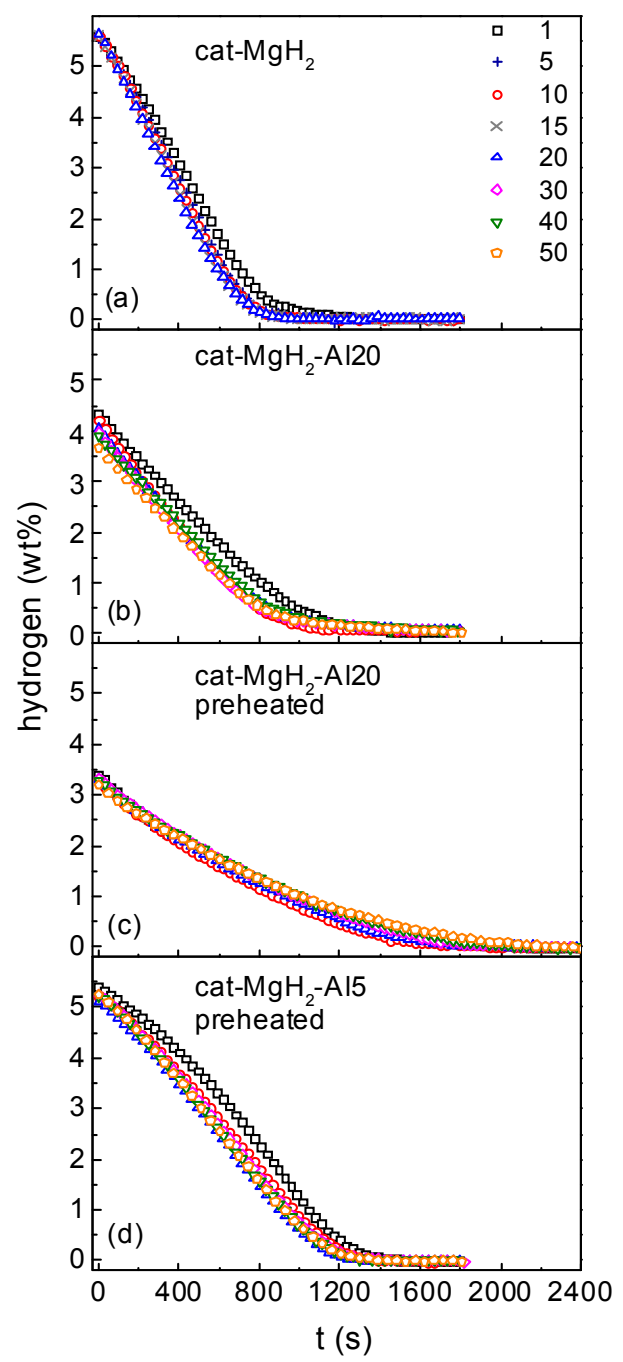

Figure 1: Desorption cycles of pellets cat- $\mathrm{MgH}_{2}$ (a), cat-MgH $\mathrm{MLI}_{2}-\mathrm{AlO}$ without preheating (b), cat- $\mathrm{MgH}_{2}-\mathrm{Al} 20$ with preheating (c) and cat- $\mathrm{MgH}_{2}-\mathrm{Al} 5$ with preheating (d). 
Figure 1a) shows the release kinetics for the pellet of cat- $\mathrm{MgH}_{2}$ and indicates that the maximum stored and released hydrogen in this case was $5.6 \mathrm{wt} \%$, which remained stable for all the hydrogen a/d cycles. During cycling, the pellet lost gradually its mechanical consistency and after 20 cycles got completely powdered. This behaviour is in agreement with the observed continuous reduction of desorption time by cycling, considering that a not close compacted powder favours the hydrogen flow through the material. The breaking of the pellets is due to the stress induced during absorption with an increase of $32 \%$ of the volume for the host $\mathrm{Mg}$ forming $\mathrm{MgH}_{2}$.

Figure $1 \mathrm{~b}$ gives the desorption curves for pellet cat- $\mathrm{MgH}_{2}-\mathrm{Al} 20$, where is shown that the hydrogen content goes from the initial $4.3 \mathrm{wt} \%$ to about $3.6 \mathrm{wt} \%$ after 50 cycles. This decrease can be explained in terms of $\mathrm{Mg}-\mathrm{Al}$ phases formation during cycling, slowly reacting with hydrogen due to a higher plateau pressure with respect to pure $\mathrm{Mg}$. The compactness of this pellet started degrading before 20 cycles and was completely lost before 50 cycles. Another similar pellet was then first heated in vacuum at $450^{\circ} \mathrm{C}$, for 10 minutes, in order to facilitate the formation of some intermetallic phases and/or solid solution and then submitted to $50 \mathrm{a} / \mathrm{d}$ cycles. As shown in figure 1c, the maximum hydrogen content of this pellet was about $3.3 \mathrm{wt} \%$ and the time for $90 \%$ desorption increased to $1320 \mathrm{~s}$. The hydrogen content was now almost constant under cycling, in contrast to the pellet without pre-heating, and the degradation of mechanical compactness resulted less. However, the pellet started to degrade before about 50 cycles. Cat- $\mathrm{MgH}_{2}$-Al5 pellets were cycled under similar conditions after pre-heating as in the previous case. Figure $1 \mathrm{~d}$ shows that in this case almost all the absorbed hydrogen (5.3 wt\%) was released in about $1500 \mathrm{~s}$. The desorption behaviour became almost stable just after 10 cycles and the pellet remained mechanically consistent and hard even after 50 cycles.

The XRD measurements of cat- $\mathrm{MgH}_{2}-\mathrm{Al} 5$ and cat- $\mathrm{MgH}_{2}-\mathrm{Al} 20$ hydrogenated and dehydrogenated pellets after heat treatment and 50 hydrogen a/d cycles give the relative abundance of the phases, estimated by means of the Rietveld refinement, reported in Table 1. These results agree with the study of hydrogenation process of ball milled Mg-Al powders by Crivello et al. [5,6], which occurs in two completely reversible steps:

$$
\begin{aligned}
& \mathrm{Al}_{12} \mathrm{Mg}_{17}+9 \mathrm{H}_{2} \leftrightarrow 9 \mathrm{MgH}_{2}+4 \mathrm{Al}_{3} \mathrm{Mg}_{2} \\
& 4 \mathrm{Al}_{3} \mathrm{Mg}_{2}+8 \mathrm{H}_{2} \leftrightarrow 8 \mathrm{MgH}_{2}+12 \mathrm{Al}
\end{aligned}
$$

Reaction (2) did not reach completion in our operating conditions, probably due to the higher relevant plateau pressure. The estimated amount of $\mathrm{Al}(4 \mathrm{wt} \%)$ in the cat-MgH $\mathrm{H}_{2}-\mathrm{Al} 20$ hydrogenated sample is larger than in the case of dehydrogenated sample. This is due to the fact that a certain amount of $\mathrm{Al}$ is in solid solution in the structure of $\mathrm{Mg}$ and during hydrogenation is expelled, according to the disproportionation reaction

$$
\operatorname{Mg}\left(\mathrm{Al}_{x}\right)+\mathrm{H}_{2} \leftrightarrow \mathrm{MgH}_{2}+x \mathrm{Al}
$$


Table 1: Results of Rietveld refinement of the XRD patterns of the cycled pellets.

\begin{tabular}{|l|c|c|c|c|c|c|}
\hline \multicolumn{1}{|c|}{ Sample } & $\begin{array}{c}\boldsymbol{\beta}-\mathbf{M g H}_{\mathbf{2}} \\
(\mathbf{w t} \%)\end{array}$ & $\begin{array}{c}\mathbf{M g} \\
(\mathbf{w t} \%)\end{array}$ & $\begin{array}{c}\mathbf{M g O} \\
(\mathbf{w t} \%)\end{array}$ & $\begin{array}{c}\mathrm{Al} \\
(\mathbf{w t} \%)\end{array}$ & $\begin{array}{c}\mathbf{A l}_{3} \mathbf{M g}_{\mathbf{2}} \\
(\mathbf{w t} \%)\end{array}$ & $\begin{array}{c}\mathbf{A l}_{12} \mathbf{M g}_{17} \\
(\mathbf{w t} \%)\end{array}$ \\
\hline cat- $\mathrm{MgH}_{2}-\mathrm{Al} 20450{ }^{\circ} \mathrm{C}$ (dehydrogenated) & $<2$ & 39 & 14 & $<3$ & - & 43 \\
\hline cat- $\mathrm{MgH}_{2}-\mathrm{Al} 20450{ }^{\circ} \mathrm{C}$ (hydrogenated) & 51 & & 17 & 4 & 15 & 13 \\
\hline cat- $\mathrm{MgH}_{2}-\mathrm{Al} 5450{ }^{\circ} \mathrm{C}$ (dehydrogenated) & 5 & 73 & 22 & - & - & - \\
\hline cat- $\mathrm{MgH}_{2}-\mathrm{Al} 5450{ }^{\circ} \mathrm{C}$ (hydrogenated) & 72 & 7 & 18 & $<3$ & - & - \\
\hline
\end{tabular}

According to the Mg-Al phase diagram, the small amount of $\mathrm{Al}$ is not sufficient for the precipitation of the eutectic phase and leads only to a solid solution of $\mathrm{Al}$ in $\mathrm{Mg}$. The presence of $\mathrm{Al}$ in solid solution is also supported by the fact that the estimated amount of $\mathrm{Al}$ in the dehydrogenated sample is negligible.

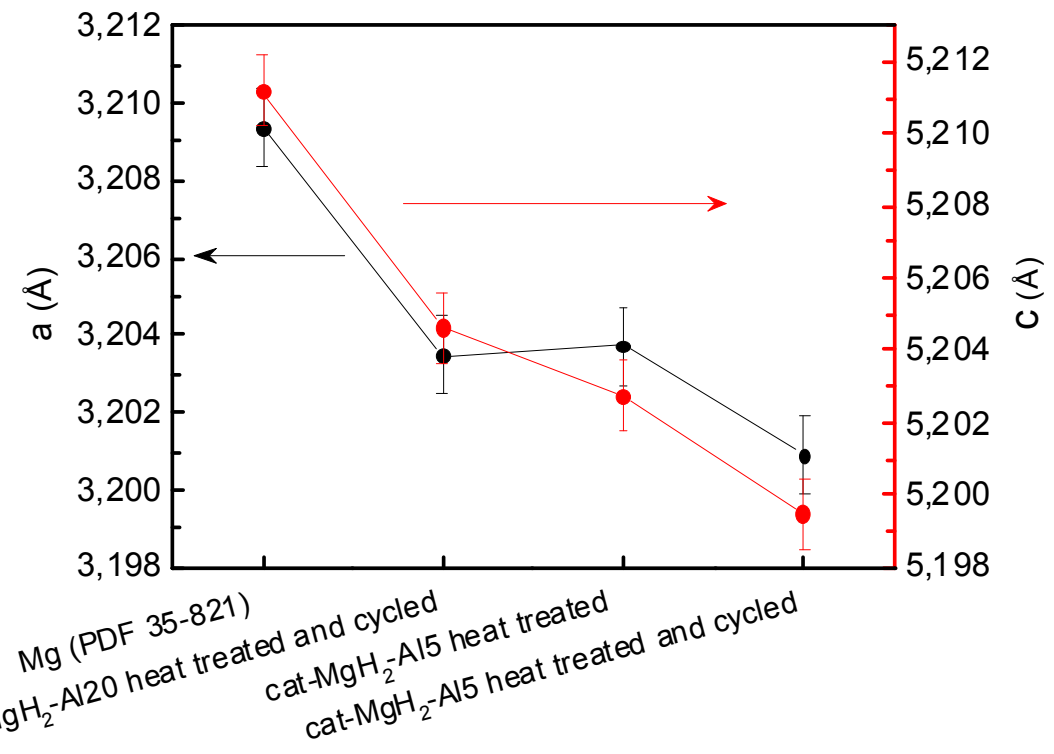

Figure 2: Lattice parameters of Mg estimated by Rietveld refinement for some of the studied dehydrogenated samples.

The lattice parameters of $\mathrm{Mg}$ obtained by the Rietveld refinement for some of the dehydrogenated samples are shown in Figure 2. These values are smaller compared to those of pure $\mathrm{Mg}$ and this is certainly due to the presence of $\mathrm{Al}$ in $\mathrm{Mg}(\mathrm{Al})$ solid solution, considering the smaller metallic radius of $\mathrm{Al}$ compared to that of $\mathrm{Mg}$. The smallest lattice parameters are observed for the cat- $\mathrm{MgH}_{2}-\mathrm{Al} 5$ sample after heat treatment and $50 \mathrm{a} / \mathrm{d}$ cycles, which shows that in this case Al prefers to enter in the $\mathrm{Mg}(\mathrm{Al})$ solid solution instead of forming Mg-Al intermetallic phases. On the contrary, in the case of the cat- $\mathrm{MgH}_{2}-\mathrm{Al} 20$ sample the precipitation of the eutectic phase $\mathrm{Al}_{12} \mathrm{Mg}_{17}$ slows down the formation of $\mathrm{Mg}(\mathrm{Al})$ and the lattice parameters of $\mathrm{Mg}$ are larger. 
Figure 3 shows the results of the mechanical tests for hydrogenated pellets without $\mathrm{Al}$ and with $5 \mathrm{wt} \% \mathrm{Al}$ after 0 and $50 \mathrm{a} / \mathrm{d}$ cycles. It is evident the better behaviour of pellets containing Al, while, in absence of aluminium, a stress of $30.1 \mathrm{~N} / \mathrm{mm}^{2}$ and of $8.1 \mathrm{~N} / \mathrm{mm}^{2}$ was sufficient to break the pellet after 10 and 20 a/d cycles, respectively. As said before, it was not possible to recover the pellet after $50 \mathrm{a} / \mathrm{d}$ cycles. The better behaviour of samples containing $\mathrm{Al}$ can be attributed to the presence, according to reaction (3), of an Al matrix surrounding the $\mathrm{MgH}_{2}$ particles. Anyway, also in this case the strength decreases, likely due to the progressive increase of porosity: $43.7 \mathrm{~N} / \mathrm{mm}^{2}$ and $13.9 \mathrm{~N} / \mathrm{mm}^{2}$ after 20 and 50 cycles, respectively.

Work is in progress to better understand, with a high resolution investigation, the microstructural evolution of the pellets in the different stages of $a / d$ cycling. Moreover, the preparation of a small vessel to study the hydrogen a/d behaviour of a metal hydride in form of pellets instead of powder, in order to overcome the shortcomings of the scaling up effects, is under way.

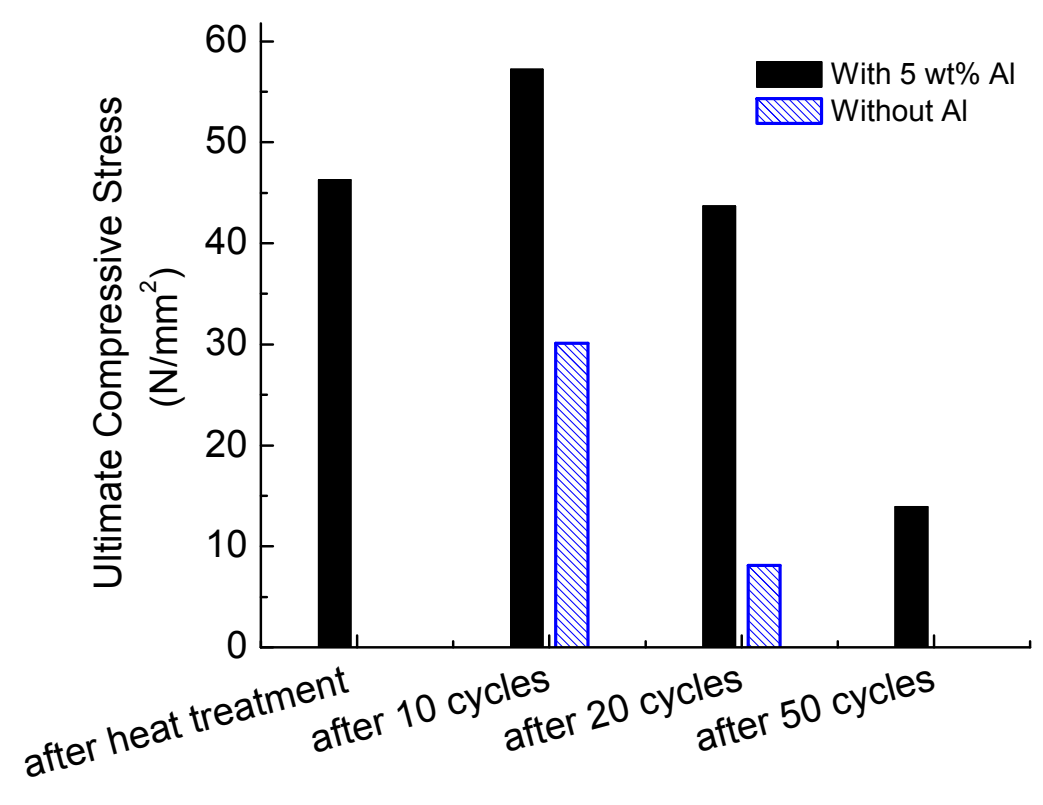

Figure 3: Results of the compression tests to estimate the mechanical strength of the pellets without and with $5 \mathrm{wt} \%$ Al.

\section{References}

[1] Barkhordarian G, Klassen T, Bormann R. Fast hydrogen sorption kinetics of nanocrystalline $\mathrm{Mg}$ using $\mathrm{Nb}_{2} \mathrm{O}_{5}$ as catalyst. Scr Mater 2003;49:213-7.

[2] De Piccoli C, Dal Toé S, Lo Russo S, Maddalena A, Palade P, Saber A, Sartori S, Principi $G$. Hydrogen storage in magnesium hydride doped with niobium pentaoxide and graphite. Chem Eng Trans 2004;4:343-7. 
[3] Verga M, Armanasco F, Guardamagna C, Valli C, Bianchin A, Agresti F, Lo Russo S, Maddalena A, Principi G. Scaling up effects of Mg hydride in a temperature and pressure-controlled hydrogen storage device. Int J Hydrogen Energy 2009;34:4602-10.

[4] Glage A, Ceccato R, Lonardelli I, Girardi F, Agresti F, Principi G, Molinari A, Gialanella $\mathrm{S}, \mathrm{A}$ powder metallurgy approach for the production of a $\mathrm{MgH}_{2}-\mathrm{Al}$ composite material, $\mathrm{J}$ Alloys Compd 2009;478:273-280.

[5] Crivello JC, Nobuki T, Kato S, Abe M, and Kuji T. Hydrogen absorption properties of the $\mathrm{y}-\mathrm{Mg}_{17} \mathrm{Al}_{12}$ phase and its Al-richer domain. J Alloys Compd 2007;446:157-61.

[6] Crivello JC, Nobuki T, Kuji T. Improvement of Mg-Al alloys for hydrogen storage applications. Int J Hydrogen Energy 2009;34:1937-43. 